\title{
What is the effectiveness of radiofrequency ablation in the management of patients with spinal metastases? A systematic review and meta-analysis
}

\author{
Navanith Murali ${ }^{*}{ }^{*}$, Thomas Turmezei ${ }^{1,2}$, Sumbal Bhatti ${ }^{1}$, Puja Patel ${ }^{1}$, Thomas Marshall ${ }^{2}$ and Toby Smith ${ }^{1}$
}

\begin{abstract}
Purpose: Spinal metastases are indicative of progressive cancer which can lead to vertebral body fractures and spinal cord compression. Radiofrequency ablation (RFA) treatment is infrequently used in patients with refractory pain. The aim of this systematic review is to determine the clinical efficacy of RFA, with the scope of using it as front-line management of spinal metastases.

Methods: Electronic databases were searched (to July 2020) for studies evaluating RFA treatment for spinal metastases in adults. Measured outcomes were pain (primary), disability, health-related quality of life (HRQOL), complications, tumour control and mortality. Study inclusion, data extraction and risk of bias using the ROBIN-I tool were assessed. Meta-analysis was conducted for pooled results with homogeneity, and narrative synthesis was conducted otherwise.

Results: 15 studies were included. RFA reduces pain scores at 3-5 weeks [standardised mean difference (SMD 2.24, 95\% confidence intervals (CI) 1.55-2.93], 3-4 months (SMD 3.00, 95\% Cl 1.11-4.90) and 5-6 months (SMD 3.54, 95\% Cl 1.96-5.11). RFA is effective in reducing disability/improving HRQOL in the short-term but longer-term efficacy remains unclear. $13.2 \%$ cases reported local tumour control failure (2.5 months-5 year follow-up) whereas mortality was $23.6 \%$ (follow-up of up to 1 year).

Conclusion: Low quality evidence has proven RFA to be safe and effective in reducing pain and disability, especially in the short-term. RFA may be routinely implemented in all cases involving refractory pain or radiotherapy-resistant tumours but controlled trials are required to compare the efficacy of RFA to current frontline treatments.

PROSPERO protocol registration number: CRD42020202377.
\end{abstract}

Keywords: Spinal metastases, Radiofrequency ablation, Spinal cord compression, Back pain, Radiotherapy

\section{Introduction}

Bone is the most common site of metastases, affecting approximately two-thirds of cancer patients [1]. The spine is by far the most common site, making up approximately $90 \%$ of spinal masses found on imaging, with the

*Correspondence: N.Murali@uea.ac.uk

${ }^{1}$ Norwich Medical School, University of East Anglia, Norwich, UK

Full list of author information is available at the end of the article most common primary cancers being prostate, breast, lung, kidney and thyroid tumours [2]. They clinically present with back pain and can cause metastatic spinal cord compression (MSCC) as a consequence of collapse/ fracture of the affected vertebral body $[3,4]$. MSCC is an oncological emergency that occurs in approximately $10 \%$ of those with spinal metastases and must be treated swiftly as it can be extremely debilitating from permanent neurological deficit [5]. original author(s) and the source, provide a link to the Creative Commons licence, and indicate if changes were made. The images or other third party material in this article are included in the article's Creative Commons licence, unless indicated otherwise in a credit line to the material. If material is not included in the article's Creative Commons licence and your intended use is not permitted by statutory regulation or exceeds the permitted use, you will need to obtain permission directly from the copyright holder. To view a copy of this licence, visit http://creativecommons.org/licenses/by/4.0/. The Creative Commons Public Domain Dedication waiver (http://creativeco mmons.org/publicdomain/zero/1.0/) applies to the data made available in this article, unless otherwise stated in a credit line to the data. 
In most cases, spinal metastases are a sign of incurable disease, and treatment is often palliative. According to current National Institute for Health and Care Excellence (NICE) guidelines on spinal metastases, those with painful spinal metastases without MSCC may be offered analgesia, bisphosphonates, radiotherapy, cement augmentation or surgery[6].

An alternative but not widely available treatment for spinal metastatic disease is radiofrequency ablation (RFA). RFA is an image-guided, minimally invasive procedure. It uses heat generated from current flowing through a probe (unipolar) or probes (bipolar), which upon contact with the target tumour causes coagulative necrosis and cell death [7]. Kyphoplasty and vertebroplasty are procedures often performed alongside RFA to augment the affected vertebral body and prevent further collapse [8].

At present, RFA is only used as a treatment for spinal metastases for some cases at the discretion of the spinal multidisciplinary team. The patient's pain, prior treatments, performance status, radioresistant status of the tumour and imaging features all help determine their suitability for RFA [9].

The purpose of this systematic review is to assess the clinical efficacy (pain, quality of life, complications, mortality, tumour control) of RFA in treatment of spinal metastases with/without radiotherapy or radiotherapy alone. Although there has been some prior research on this, there is little collated evidence on long-term outcomes such as tumour recurrence and mortality $[10,11]$, which this study seeks to address, as well as meta-analysing the clinical outcomes.

\section{Methods}

This systematic review was conducted in accordance with the PRISMA statement on preferred reporting items on systematic reviews and meta-analyses [12]. The protocol was registered on to PROSPERO (registration number: CRD42020202377).

\section{Outcomes}

The primary outcomes measured were pain, disability and health-related quality of life (HRQOL). These are quantified in terms of Visual Analogue Scale (VAS) for pain and the Oswestry disability Index (ODI). The definitions of short-, mid- and long-term outcomes were subject to change once all data from included studies had been pooled.

Our secondary outcome measures were (1) tumour control/recurrence of spinal metastases; (2) mortality; and (3) complication rates.

\section{Information sources and search strategy}

Ovid MEDLINE, EMBASE, CENTRAL databases were used to find published and unpublished studies from database inception to July 2020. Trial registries searched included WHO (World Health Organisation) clinical trial registry, clinicaltrials.gov and ISCTRN. Reference lists of included studies and similar systematic reviews were also searched. Both randomised and non-randomised study designs were part of the search criteria. Search terms were based on the PICOS framework [13]. Radiofrequency ablation OR RFA, spinal metastases OR spinal met" OR spin" adj3 met" were the main terms used. The PICOS framework used and an example search strategy can be found in Additional file 1 .

\section{Eligibility criteria}

To warrant inclusion, studies had to fulfil all the eligibility criteria; (1) both randomised and non-randomised comparator study designs; (2) study participants aged over 18-years-old; (3) study participants presenting with spinal metastases and have undergone treatment with RFA alone or RFA combined with another modality; (4) study outcomes observing our measured outcomes. Studies that only included data for primary spinal tumours, animals and RFA assisted open surgery were excluded.

\section{Quality assessment and Data extraction}

Quality of included studies was using the Risk of Bias In Non-randomised Studies of Interventions (ROBINS-1) tool [14]. Data were extracted for: date, country of publication, trial design, participant baseline characteristics i.e. age, gender, tumour type, any additional treatments, intervention, RFA system used, co-interventions to RFA (including cement augmentation), treatment complication rates and all clinical outcomes of interest. Quality assessment and data extraction were conducted independently by two authors (NM and $\mathrm{PP}$ ) and verified by a third reviewer (SB). An initial pilot extraction involving two studies was undertaken by all three reviewers before proceeding. Full data extraction tables can be found in Additional file 1.

\section{Data synthesis analysis}

In the instance where there was substantial heterogeneity between studies for study design, participant characteristics or interventions delivered, these data were analysed narratively. Where there was homogeneity, a meta-analysis was conducted for outcomes reported by two or more studies. Given the natural variability in clinical presentation and comorbid disease in people who experience spinal metastases, a random-effects model was adopted for all meta-analyses. Statistical 
heterogeneity was measured by the $\mathrm{I}^{2}$ statistic. For continuous data, meta-analyses were reported as standardised mean differences (SMD) with 95\% confidence intervals $(\mathrm{CI})$ and a forest plot for the primary outcome. All meta-analyses were conducted on RevMan (version 5.4.1, The Cochrane Collaboration, UK) [15].

Subgroup analysis was carried out to explore if there was substantial heterogeneity. These subgroups included patient age, type of primary cancer and RFA combination received.

Meta-analysed outcomes were assessed against the GRADE approach. Through this, each reported outcome was upgraded or downgraded by: risk of bias; imprecision; inconsistency; indirectness; and publication bias. Through this, each outcome was assessed as: very low; low; moderate or high certainty evidence.

\section{Results}

Study selection and characteristics

The PRISMA flow diagram (Fig. 1) portrays the process of study selection [16]. Fifteen studies were included for this systematic review [17-31].

Study characteristics are summarised in Table 1 . The 15 eligible studies involved a total of 725 patients. Only

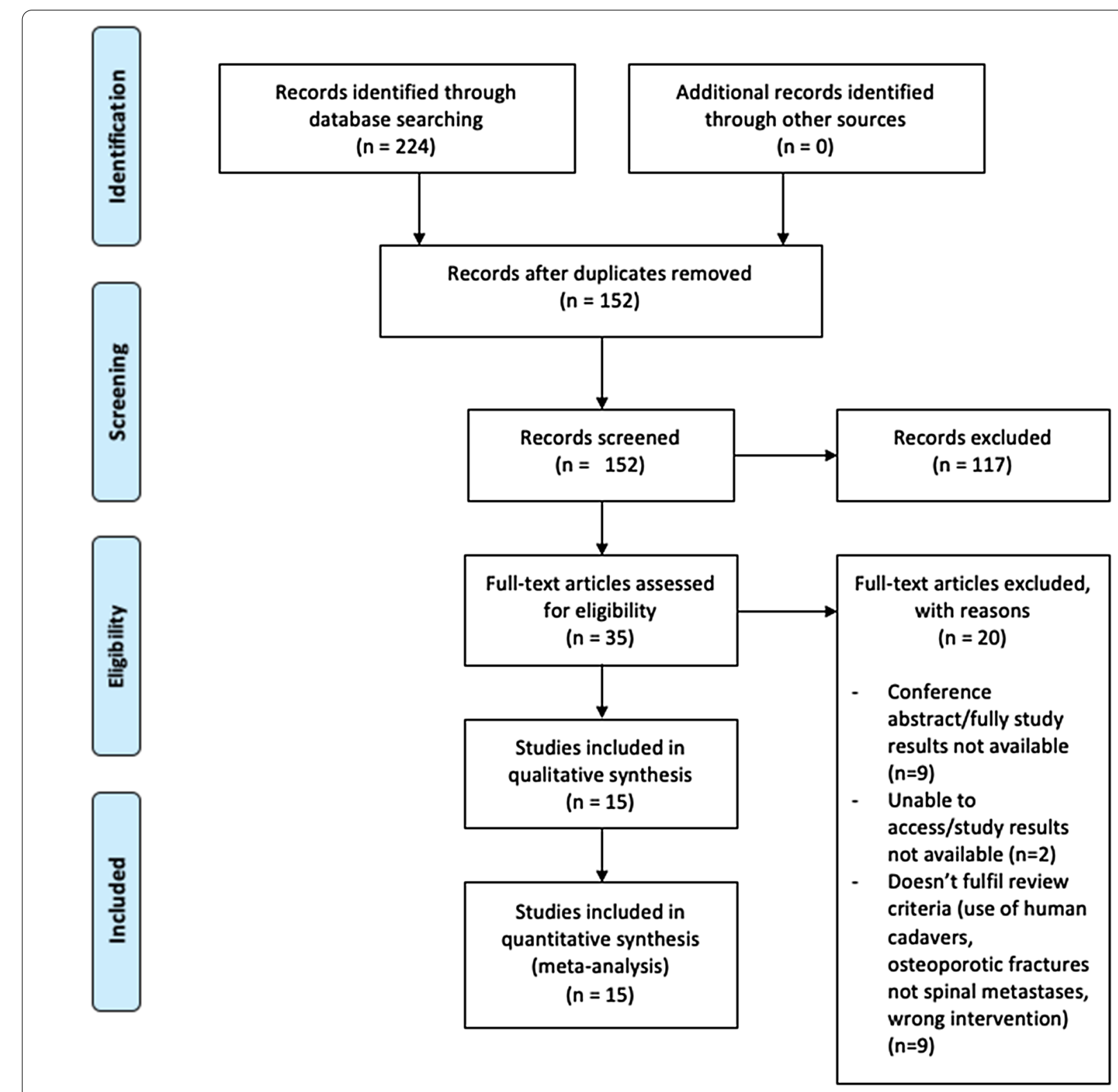

Fig. 1 PRISMA flow diagram depicting literature search and study inclusion 


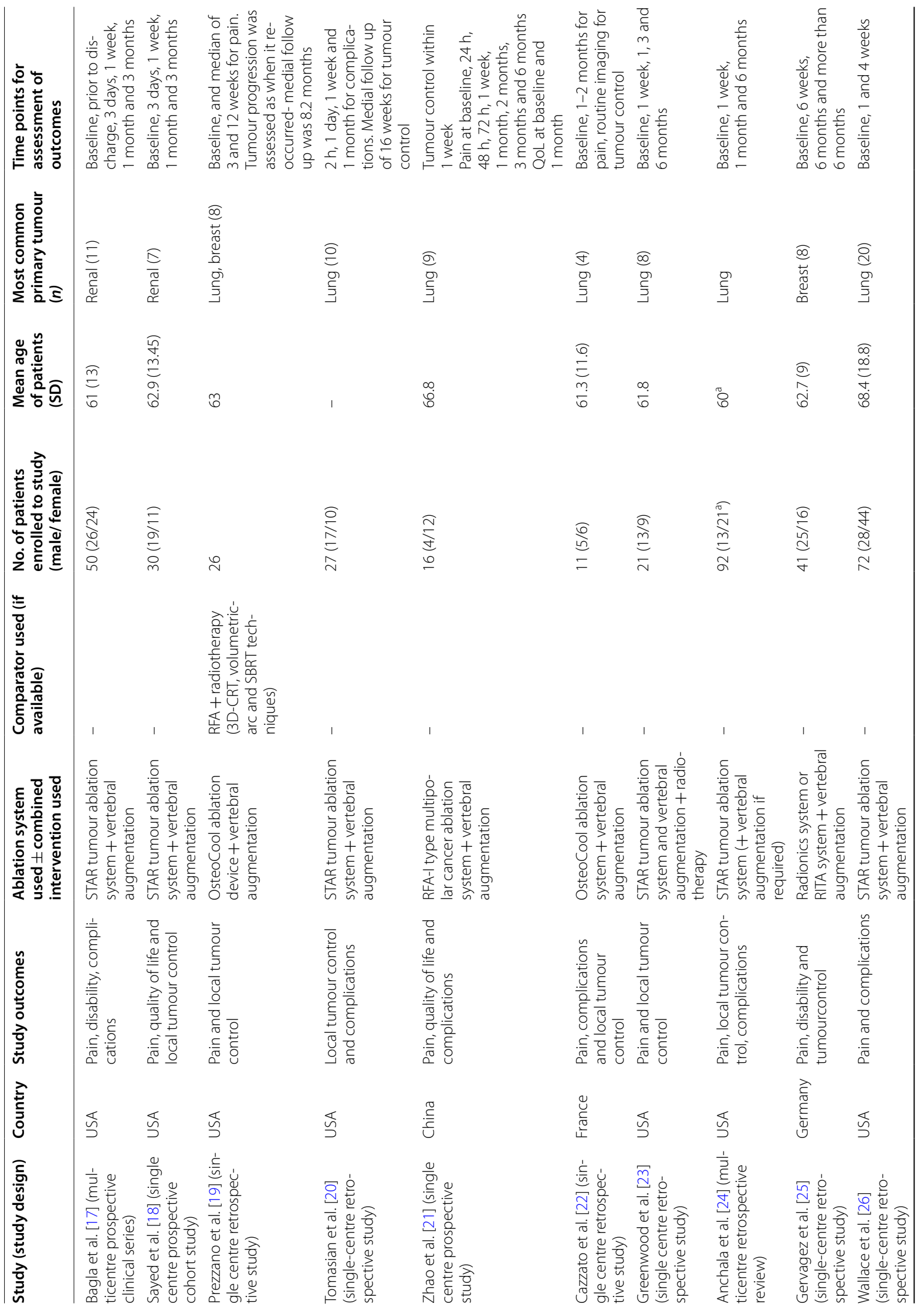




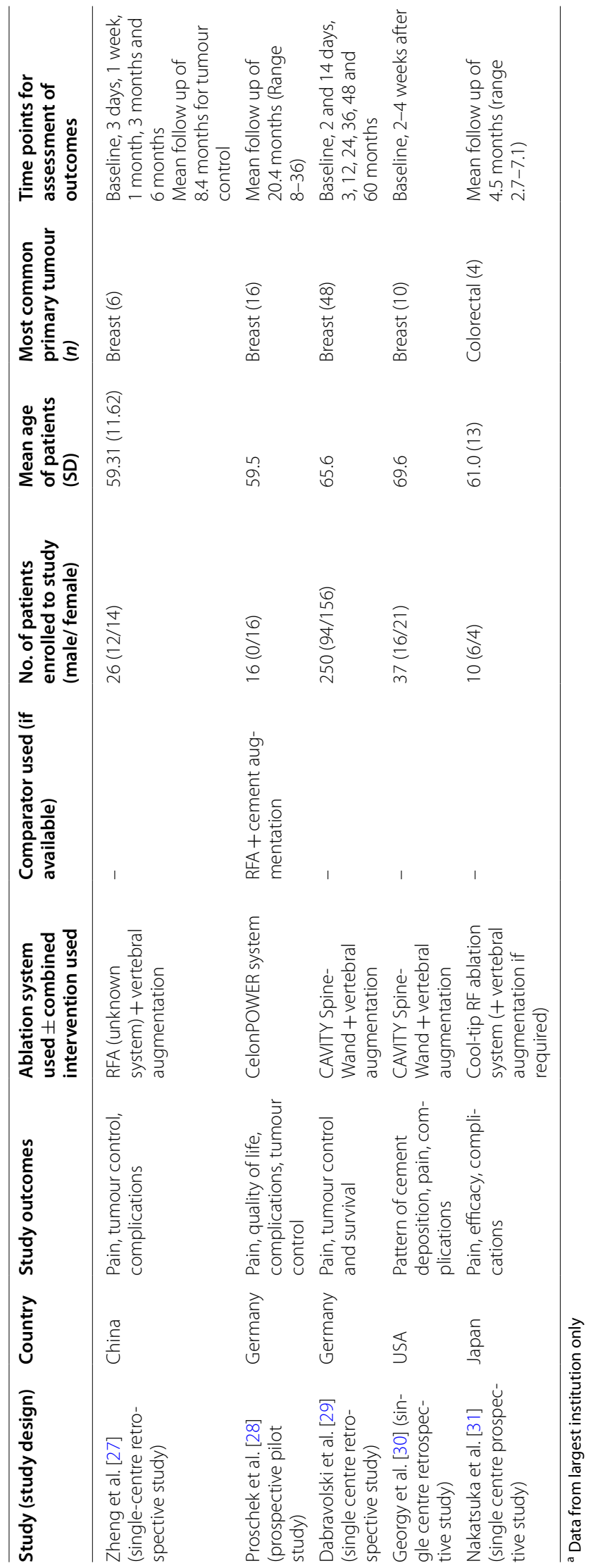


two studies were comparative in nature; Prezzano et al. compared outcomes for RFA and cement augmentation versus RFA and radiotherapy[19] whereas Proschek et al. compared RFA by itself to RFA with cement augmentation [28]. All other studies observed outcomes for one group all receiving the same RFA intervention. Fourteen studies measured pain outcomes. Five studies measured disability/quality of life outcomes. Ten studies also observed tumour control as an outcome, and 10 studies also included mortality statistics. The most common primary tumours for patients in the studies included were breast, renal and lung neoplasms. All studies included were non-randomised.

Summary of risk of bias assessment is summarised in Table 2. All studies were assessed as serious risk for bias overall mainly due to confounding factors, subjectivity in measurement of outcomes and high dropout rate. The overall strength of evidence using the GRADE approach ranged from 'low' to 'very low' (Additional file 1).
Pain

Altogether, nine studies included pain data which could be statistically pooled for meta-analyses $[18,19,21-24$, $26,27,31]$. Though there was high methodological heterogeneity due to the serious risk of bias in non-randomised studies, the clinical diversity among these studies was quite similar as participants had similar ages, similar RFA systems being used and similar primary tumours. We could not conduct any sub-group analyses as the majority of these studies only included pooled data and no individual pain scores. Time points for short-, mid- and long-term pain were adjusted to 3-5 weeks, 3-4 and 5-6 months, respectively, to allow for pooling (Additional file 1).

\section{Effect of radiofrequency ablation on short-term pain}

Eight studies included pain scores at 3-5 weeks followup which could be statistically pooled $[18,19,21-24,26$, 27]. Evidence of low quality showed that RFA improves pain short-term as portrayed by the reduction in VAS

Table 2 Quality assessment of included studies using ROBINS-1 tool

\begin{tabular}{|c|c|c|c|c|c|c|c|c|}
\hline Study & $\begin{array}{l}\text { Bias due to } \\
\text { confounding }\end{array}$ & $\begin{array}{l}\text { Bias in } \\
\text { selection of } \\
\text { participants } \\
\text { into study }\end{array}$ & $\begin{array}{l}\text { Bias in } \\
\text { classification } \\
\text { of } \\
\text { interventions }\end{array}$ & $\begin{array}{l}\text { Bias due to } \\
\text { deviations } \\
\text { from } \\
\text { intended } \\
\text { interventions }\end{array}$ & $\begin{array}{l}\text { Bias due } \\
\text { to missing } \\
\text { data }\end{array}$ & $\begin{array}{l}\text { Bias in } \\
\text { measurement } \\
\text { of outcomes }\end{array}$ & $\begin{array}{l}\text { Bias in } \\
\text { selection of } \\
\text { the reported } \\
\text { result }\end{array}$ & $\begin{array}{l}\text { Overall risk of } \\
\text { bias }\end{array}$ \\
\hline Bagla et al. [17] & Serious & Low & Low & Low & Moderate & Serious & Low & Serious \\
\hline Sayed et al. [18] & Serious & Low & Low & Low & Moderate & Serious & Low & Serious \\
\hline $\begin{array}{l}\text { Prezzano et al. } \\
\text { [19] }\end{array}$ & Serious & Low & Low & Low & Low & Serious & Low & Serious \\
\hline $\begin{array}{l}\text { Tomasian et al. } \\
{[20]}\end{array}$ & Serious & Low & Low & Low & Moderate & Low & Low & Serious \\
\hline Zhao et al. [21] & Serious & Low & Low & Low & Low & Serious & Low & Serious \\
\hline $\begin{array}{l}\text { Cazzato et al. } \\
\text { [22] }\end{array}$ & Serious & Moderate & Low & Low & Low & Serious & Low & Serious \\
\hline $\begin{array}{l}\text { Greenwood } \\
\text { et al. [23] }\end{array}$ & Serious & Low & Low & Low & Low & Serious & Low & Serious \\
\hline $\begin{array}{l}\text { Anchala et al. } \\
\text { [24] }\end{array}$ & Serious & Low & Low & Low & Moderate & Serious & Low & Serious \\
\hline $\begin{array}{l}\text { Gervagez et al. } \\
{[25]}\end{array}$ & Serious & Low & Low & Low & Serious & Serious & Low & Serious \\
\hline $\begin{array}{l}\text { Wallace et al. } \\
\text { [26] }\end{array}$ & Serious & Low & Low & Low & Low & Serious & Low & Serious \\
\hline $\begin{array}{l}\text { Zheng et al. } \\
\text { [27] }\end{array}$ & Serious & Low & Low & Low & Low & Serious & Low & Serious \\
\hline $\begin{array}{l}\text { Proschek et al. } \\
\text { [28] }\end{array}$ & Moderate & Low & Low & Low & Low & Serious & Low & Serious \\
\hline $\begin{array}{l}\text { Dabravolski } \\
\text { et al. [29] }\end{array}$ & Serious & Low & Low & Low & Low & Serious & Low & Serious \\
\hline $\begin{array}{l}\text { Georgy et al. } \\
\text { [30] }\end{array}$ & Serious & Low & Low & Low & Moderate & Serious & Low & Serious \\
\hline $\begin{array}{l}\text { Nakatsuka } \\
\text { et al. [31] }\end{array}$ & Serious & Low & Low & Low & Low & Serious & Low & Serious \\
\hline
\end{tabular}


score at 3-5 weeks difference (SMD 2.24, 95\% CI 1.55$2.93, \mathrm{I}^{2}=89 \%$, eight studies, 286 participants).

\section{Effect of radiofrequency ablation on mid-term pain:} Four studies included pain data at 3-4 months follow-up which could be pooled [18, 19, 21, 27]. Evidence of very low strength showed that RFA also improves pain midterm (SMD 3.00, 95\% CI 1.11-4.90, I $\mathrm{I}^{2}=95 \%$, four studies, 98 participants). Though there is a clear improvement in pain at this time-point, the extent to which it is paineffective is unclear due to wide confidence intervals.

\section{Effect of radiofrequency ablation on long-term pain:}

Four studies included pain data at 5-6 months followup [21, 23, 26, 31]. Evidence of very low strength showed that RFA does improve pain with reduced VAS scores longer-term (SMD 3.54, 95\% CI 1.96-5.11, $\mathrm{I}^{2}=88 \%$, four studies, 144 participants). Similar to the mid-term outcome, the confidence interval is wide but still shows an overall significant reduction in pain 5-6 months following RFA.

\section{Disability and Health-Related Quality of Life}

Five studies measured disability or HRQOL outcomes, using a variety of scales and indexes [17, 18, 21, 25, 28]. A meta-analysis was not conducted for this outcome as only one study reported variance data and could be statistically pooled.

\section{Short-term effect of RFA on disability and HRQOL (<3 months)}

Four out of five studies reported a significant reduction in disability and/or improvement in HRQOL at less than three months of follow-up following RFA treatment. Bagla et al. reported a significant decrease in ODI score (i.e. reduction in disability) by $7.7 \%(P<0.01)$ at Day 3 of follow up and $12.9 \%$ decrease at one month follow up $(P<0.01)$ [17]. Similarly, Proschek et al. also reported a significant $30 \%$ decrease in ODI for both the RFA only arm $(P<0.014)$ and RFA plus vertebral augmentation arm $(P<0.0031)$ following RFA [28]. Gervagez et al. also reported a significant reduction in disability following RFA. This was measured as an $8 \%$ decrease in pain disability index score $(\mathrm{PDI})$ at six weeks $(P<0.015)$ [25].

Bagla also reported mean increases in FACT-G7 and FACT-BP scores (i.e. improvement in quality of life), with an increase of $4.8(P<0.0001)$ and $14.7(P<0.0001)$ at one month, respectively [17]. Sayed et al. also measured FACT-G7 scores but did not observe a significant difference [18]. Zhao et al. reported significant improvements in physical function $(P=0.03)$ and emotion function $(P=0.003)$ using the EORTC QLQ-C30 scale at one month follow-up [21].

\section{Mid-term effect of RFA on disability and HRQOL} (3-12 months)

Four studies measured disability and/or HRQOL outcomes at 3-12 months. At three months, Bagla et al. and Gervagez et al. reported a $15.9 \%$ decrease in ODI $(P<0.01)$, and a $4 \%$ decrease in PDI [0.002] scores, respectively $[17,25]$. Sayed et al. did not observe a significant improvement in FACT-G7 score at three months post-RFA. $(P=0.071)$, whereas Proschek et al. did not find a significant reduction in mean ODI score at 3-6 months follow-up $(P=0.06)[18,28]$.

\section{Long-term effect of RFA on disability and HRQOL (>12 months)}

Only Proschek et al. reported disability and HRQOL outcomes past 12 months [28]. It concluded that there was not a significant decrease in ODI scores at follow up of $15-36$ months $(P=0.071)$. Gervagez et al. also reported a $10 \%$ decrease in PDI at over six months of follow up $(P=0.003)$ [25]. Since the exact follow up period was not stated, we cannot determine whether this decrease would fall under mid- or long-term effect RFA.

\section{Complications}

All studies except one included complication data [19]. Cement extravasation was by far the most common complication, occurring in $10.3 \%$ of cases. Out of these seventy-two occurrences, only one was deemed clinically significant, causing moderate pain and requiring surgical removal [21]. Other complications reported were radicular pain, paraplegia and transient neural damage, all of which were temporary. Cazzato et al. reported the only case of sepsis, which is a major complication and resulted in death of the patient [22]. In this case, the patient received RFA despite having a subclinical paravertebral abscess which was misdiagnosed. Excluding this human error, radiofrequency ablation for the treatment of spinal metastases has otherwise proven to be safe.

\section{Tumour control}

Ten studies reported data on tumour control and recurrence [18-20, 22-25, 27-29]. In total, 51 out of 387 patients (13.2\%) showed failure of tumour control or demonstrated tumour recurrence (2.5 month to five years follow up). It must be noted that the differences in tumour histology and follow-up periods between the studies will likely have affected this result. 


\section{Mortality}

Ten studies included mortality data $[17,19-23,26,27$, $29,31]$. Out of 462 participants, 109 died $(23.6 \%)$ at a median/mean follow of up to one year.

Bagla et al. and Tomasian et al. both attributed the deaths of the 13 patients in their studies to causes unrelated to procedure[17-20], and post-operative sepsis was the cause of the single death in Cazzato et al. [22]. Cause of death was not mentioned in the rest of the studies. Dabravolski et al. [29] provided survival data for up to five years; $34.1 \%$ of patients died within one year, $58.9 \%$ of patients died within two years, $76.9 \%$ at three years, $83.8 \%$ at four years and $85.1 \%$ at five years.

Due to the ambiguity in the cause of deaths and the already reduced life expectancy of those with metastatic cancer, it is difficult to form a strong association between RFA and survival.

\section{RFA alone versus RFA and radiotherapy}

Two studies observed RFA combined with radiotherapy (RT) specifically as a combined multimodality treatment [19-23]. Prezzano et al. determined a case as RFA plus RT if patients had received RT to the same spinal level they had received RFA without any local progression. Greenwood et al. determined a case as RFA plus RT if they received either of the treatments to the same level within four weeks of each other. Both studies observed a significant pain reduction in such circumstances. Prezzano et al. also included a control group which received RFA by itself and found there was no significant difference in VAS scores between the RFA group versus the RFA + RT group $(P=0.96)$. Though there is some evidence that RFA plus RT is effective in pain relief, it is still unclear whether it is more effective as a combination treatment compared to RFA alone.

Prezzano et al. also measured tumour control and survival data for both RFA and RFA plus RT groups [19]. The RFA plus RT group showed better local tumour control ( $1 / 11$ patients had local failure in RFA + RT group versus $8 / 17$ in RFA only group). Median survival was also longer in the combination group (55.3 weeks vs 31.9 weeks in RFA only group).

\section{Discussion}

The primary objective of this systematic review was to assess the clinical efficacy of RFA in patients with spinal metastases. We report that radiofrequency ablation, whether by itself or with combination treatment, has some evidence that it is effective in reducing pain and disability in patients with spinal metastases, especially in the short-term. The extent to which RFA reduces pain is unclear in the mid- and long-term due to the wide confidence intervals in the meta-analyses. This is similar for disability and HRQOL as results are unclear at longer time points. Since patients with spinal metastases are at an advanced stage of cancer, it is understandable for disability and HRQOL outcomes to worsen with mid- and long-term outcomes due to progression of other cancerrelated sequelae. Except for one case of sepsis which was attributed to human error, there were no major complications attributed to the RFA procedure itself, and therefore, all studies deemed it to be safe.

The two previous systematic reviews conducted on this subject found that RFA may be safe and effective as analgesia in the short-term (one week to six months) $[10,11]$. The results of this review and meta-analysis support and further this by analysing deeper into outcomes such as disability, tumour control and mortality while also finding minimal evidence for RFA in combination with RT.

We are unable to draw any clear conclusions on the effect of RFA on local tumour control and mortality. The difference in follow-up period between studies is likely to obscure the true effect of RFA on tumour control as participants in longer follow-up studies might be at increased risk of local failure due to the progressive nature of metastatic cancer. This was also the case for mortality data. Additionally, many of the studies that reported mortality data did not mention cause of death, so we could only group this data as all-cause mortality.

Our second objective was to assess the efficacy of RFA as combined treatment with another intervention. Though there was evidence to suggest RFA is more effective combined with radiotherapy, it remains unclear if RFA with radiotherapy is more effective than RFA alone for reducing pain.

\section{Limitations}

The main limitation of this review was the statistical heterogeneity presented by the meta-analyses. This could be attributed to the methodological heterogeneity due to the serious risk of bias in all studies. Moreover, we were unable to conduct sub-group analyses to explore heterogeneity as most studies only included pooled data. Though authors were contacted for individual participant data, no response was received. As a result of this, the evidence in this review is of low quality. We also found no RCTs, so all studies included were non-randomised. Their absence in the context of spinal metastases is understandable as patients have a poor prognosis, which would likely impact on RCT recruitment and completion. As a result, confounders and lack of blinding in the included studies meant that all were assessed as serious risk of bias. One such confounder was adjuvant oncological treatments received by patients (e.g. chemotherapy) which could have affected spinal metastases outcomes irrespective of RFA. Some studies mentioned if patients 
received these treatments, but it is hard to exclude their effect without RCT design in place. Most studies also did not include a comparator group, and therefore, there was no way of knowing whether RFA improved or worsened these outcomes such as mortality unless they were compared to participants who received no RFA or a different spinal metastases treatment e.g. radiotherapy. Another limitation was the absence of a funnel plot for assessment of publication bias. This was omitted as it is not recommended when there are less than ten studies in the metaanalysis, as the power of the tests is too low to distinguish from real asymmetry [15].

\section{Implications for clinical practice and future research}

Currently, RFA is not part of NICE guidelines in the management of spinal metastases and is only used infrequently in the UK [6]. This systematic review has found evidence that RFA is a safe procedure which is effective in pain and disability reduction, especially in the shortterm. There is also some weak evidence on the benefits of RFA being combined with radiotherapy. Though there was a variety of tumour histology in each study, we believe the collated study population represented typical oncological patients who may present with spinal metastases, since many different primary tumours can metastases to the spine. With these results in mind, RFA could potentially be implemented as a treatment for refractory pain following conventional analgesia and radiotherapy, usually followed by vertebral cement augmentation as this was common practice across all included studies.

Randomised controlled trials are needed to definitively assess the efficacy of RFA compared to standard treatments such as radiotherapy by providing higher quality evidence on the true effectiveness of RFA on clinical outcomes, especially tumour control and mortality (e.g. survival analyses and including cause of death). This would provide higher quality evidence on how RFA could be used alongside or even ahead of radiotherapy. Such trials could also include participants with a specific primary tumour only, e.g. targeting spinal metastases in a typically radioresistant tumour such as renal cell carcinoma. Without such trials, it is difficult to assess the role of RFA treatment ahead of current standard treatments such as radiotherapy.

\section{Conclusion}

We report evidence of low-quality suggesting radiofrequency ablation (RFA) is safe and effective in reducing pain and disability, as well as improving quality of life in patients with spinal metastases in the short-term especially. The results of this review may justify the use of RFA in refractory cases, in particular radioresistant tumours. There is limited evidence comparing RFA to radiotherapy, and thus, we are unable to draw conclusions on tumour control and mortality without conducting higher-quality studies such as randomise control trials.

\section{Abbreviations}

RFA: Radiofrequency Ablation; HRQOL: Health-related Quality of Life; RT: Radiotherapy; Cl: Confidence interval; SMD: Standardised mean difference; NICE: National Institute for Health and Care Excellence; MSCC: Metastatic Spinal Cord Compression; VAS: Visual Analogue Scale; ODI: Oswestry Disability Index; ROBINS-1: Risk of Bias In Non-randomised Studies of Interventions; WHO: World Health Organisation.

\section{Supplementary Information}

The online version contains supplementary material available at https://doi. org/10.1186/s13018-021-02775-x.

Additional file 1. From top to bottom- Table S1. PICOS framework for the search strategy. Figure $\mathbf{S 1}$. The random-effects meta-analysis showing the effect of RFA on pain at 3-5 weeks, 3-4, and 5-6 months. There is significant pain reduction at all these time points. Table $\mathbf{S 2}$. Summary of complications reported across all included studies. Table S3. Summary of reported tumour control and mortality data across all included studies. Table S4. Example search strategy used for the CENTRAL database. Table S5. Full data extraction table for patient baseline characteristics. Table S6. Summary of GRADE approach for meta-analysed outcomes. Table S7. Data extraction table for pain, disability and HRQOL. Table S8. Full data extraction table for complications, mortality and tumour control.

\section{Acknowledgements}

I would like to thank all contributing authors for their hard work in finalising this project, especially Dr Turmezei and Dr Smith, who supervised me through writing this systematic review.

\section{Author's contributions}

The idea for this article was conceived by $T$ T and NM. NM wrote the first draft of the paper and carried out the literature search. SB and PP acted as reviewers in study selection, data extraction and quality assessment. TS carried out the meta-analysis. TT, TS and TM critically revised the review. All authors read and approved the final manuscript.

\section{Funding}

No funding was received for conducting this study.

\section{Availability of data and materials}

All data generated or analysed during this study are included in this published article (and its Additional file 1).

\section{Declarations}

\section{Ethics approval and consent to participate}

Since this is a review of previously published studies, ethical approval was not required.

Consent for publication

All authors consent to publication.

\section{Competing interests}

The authors have no conflicts of interest to declare that are relevant to the content of this article.

\section{Author details}

${ }^{1}$ Norwich Medical School, University of East Anglia, Norwich, UK. ${ }^{2}$ Department of Radiology, Norfolk \& Norwich University Hospital, Norwich, UK. 
Received: 11 August 2021 Accepted: 5 October 2021

Published online: 06 November 2021

\section{References}

1. Maccauro G, Spinelli MS, Mauro S, Perisano C, Graci C, Rosa MA. Physiopathology of spine metastasis. Int J Surg Oncol. 2011;2011: 107969. https:// doi.org/10.1155/2011/107969.

2. ZiU E, Viswanathan VK, Mesfin FB. Spinal metastasis. StatPearls [Internet]. StatPearls Publishing; 2020

3. Robson P. Metastatic spinal cord compression: a rare but important complication of cancer. Clin Med (Lond). 2014. https://doi.org/10.7861/clinm edicine.14-5-542.

4. De Vita VT, Hellman S, Rosenberg SA. Principles and practice of oncology. 11th ed. Williams and Wilkins: Lippincott; 2019.

5. Mossa-Basha M, Gerszten PC, Myrehaug S, Mayr NA, Yuh WT, Jabehdar Maralani P, Sahgal A, Lo SS. Spinal metastasis: diagnosis, management and follow-up. Br J Radiol. 2019;92(1103):20190211. https://doi.org/10. 1259/bjr.20190211.

6. National Institute for Health and Care Excellence. Metastatic spinal cord compression in adults: risk assessment, diagnosis and management | Guidance. 2021. https://www.nice.org.uk/guidance/cg75/chapter/1Guidance. Accessed 23 Feb 2021.

7. Navaneethan U, Thosani N, Goodman A, Manfredi M, Pannala R, Parsi MA, Smith ZL, Sullivan SA, Banerjee S, Maple JT. Radiofrequency ablation devices. VideoGIE. 2017;2(10):252-9. https://doi.org/10.1016/j.vgie.2017. 06.002.

8. McCall T, Cole C, Dailey A. Vertebroplasty and kyphoplasty: a comparative review of efficacy and adverse events. Curr Rev Musculoskelet Med. 2008;1(1):17-23. https://doi.org/10.1007/s12178-007-9013-0.

9. Jennings JW. Clinical utility of targeted radiofrequency ablation in spinal metastatic disease. Oncol Times. 2018;40(15):13-5. https://doi.org/10. 1097/01.COT.0000544333.45592.6d.

10. Rosian K, Hawlik K, Piso B. Efficacy assessment of radiofrequency ablation as a palliative pain treatment in patients with painful metastatic spinal lesions: a systematic review. Pain Physician. 2018;21(5):E467-76.

11. Cazzato RL, Garnon J, Caudrelier J, Rao PP, Koch G, Gangi A. Percutaneous radiofrequency ablation of painful spinal metastasis: a systematic literature assessment of analgesia and safety. Int J Hyperthermia. 2018;34(8):1272-81. https://doi.org/10.1080/02656736.2018.1425918.

12. Moher D, Liberati A, Tetzlaff J, Altman DG, The PRISMA Group. Preferred reporting items for systematic reviews and meta-analyses: the PRISMA statement. PLoS Med. 2009;6(7):e1000097. https://doi.org/10.1371/journ al.pmed1000097.

13. Methley AM, Campbell S, Chew-Graham C, McNally R, Cheraghi-Sohi S. PICO, PICOS and SPIDER: a comparison study of specificity and sensitivity in three search tools for qualitative systematic reviews. BMC Health Serv Res. 2014;21(14):579. https://doi.org/10.1186/s12913-014-0579-0.

14. Sterne JAC, Hernán MA, Reeves BC, Savović J, Berkman ND, Viswanathan M, Henry D, Altman DG, Ansari MT, Boutron I, Carpenter JR, Chan AW, Churchill R, Deeks JJ, Hróbjartsson A, Kirkham J, Jüni P, Loke YK, Pigott TD, Ramsay CR, Regidor D, Rothstein HR, Sandhu L, Santaguida PL, Schünemann HJ, Shea B, Shrier I, Tugwell P, Turner L, Valentine JC, Waddington $\mathrm{H}$, Waters E, Wells GA, Whiting PF, Higgins JPT. ROBINS-I: a tool for assessing risk of bias in non-randomized studies of interventions. BMJ. 2016:35:4419

15. Higgins JPT, Thomas J, Chandler J, Cumpston M, Li T, Page MJ, Welch VA. Cochrane handbook for systematic reviews of interventions version 6.2 . 2021. www.training.cochrane.org/handbook.

16. Liberati A, Altman DG, Tetzlaff J, Mulrow C, Gøtzsche PC, loannidis JP, Clarke M, Devereaux PJ, Kleijnen J, Moher D. The PRISMA statement for reporting systematic reviews and meta-analyses of studies that evaluate healthcare interventions: explanation and elaboration. BMJ. 2009;21 (339): b2700. https://doi.org/10.1136/bmj.b2700
17. Bagla S, Sayed D, Smirniotopoulos J, Brower J, Neal Rutledge J, Dick B, Carlisle J, Lekht I, Georgy B. Multicenter prospective clinical series evaluating radiofrequency ablation in the treatment of painful spine metastases. Cardiovasc Intervent Radiol. 2016;39(9):1289-97. https://doi.org/10.1007/ s00270-016-1400-8.

18. Sayed D, Jacobs D, Sowder T, Haines D, Orr W. Spinal radiofrequency ablation combined with cement augmentation for painful spinal vertebral metastasis: a single-center prospective study. Pain Physician. 2019;22(5):E441-9.

19. Prezzano KM, Prasad D, Hermann GM, Belal AN, Alberico RA. Radiofrequency ablation and radiation therapy improve local control in spinal metastases compared to radiofrequency ablation alone. Am J Hosp Palliat Care. 2019:36(5):417-22. https://doi.org/10.1177/1049909118819460.

20. Tomasian A, Hillen TJ, Chang RO, Jennings JW. Simultaneous bipedicular radiofrequency ablation combined with vertebral augmentation for local tumor control of spinal metastases. AJNR Am J Neuroradiol. 2018;39(9):1768-73. https://doi.org/10.3174/ajnr.A5752.

21. Zhao W, Wang H, Hu JH, Peng ZH, Chen JZ, Huang JQ, Jiang YN, Luo G, Yi GF, Shen J, Gao BL. Palliative pain relief and safety of percutaneous radiofrequency ablation combined with cement injection for bone metastasis. Jpn J Clin Oncol. 2018;48(8):753-9. https://doi.org/10.1093/jjco/hyy090.

22. Cazzato RL, Garnon J, Caudrelier J, Rao PP, Koch G, Gangi A. Lowpower bipolar radiofrequency ablation and vertebral augmentation for the palliative treatment of spinal malignancies. Int J Hyperthermia. 2018;34(8):1282-8. https://doi.org/10.1080/02656736.2017.1422557.

23. Greenwood TJ, Wallace A, Friedman MV, Hillen TJ, Robinson CG, Jennings JW. Combined ablation and radiation therapy of spinal metastases: a novel multimodality treatment approach. Pain Physician. 2015;18(6):573-81.

24. Anchala PR, Irving WD, Hillen TJ, Friedman MV, Georgy BA, Coldwell DM, Tran ND, Vrionis FD, Brook A, Jennings JW. Treatment of metastatic spinal lesions with a navigational bipolar radiofrequency ablation device: a multicenter retrospective study. Pain Physician. 2014;17(4):317-27.

25. Gevargez A, Groenemeyer DH. Image-guided radiofrequency ablation (RFA) of spinal tumors. Eur J Radiol. 2008;65(2):246-52. https://doi.org/10. 1016/j.ejrad.2007.03.026.

26. Wallace AN, Greenwood TJ, Jennings JW. Radiofrequency ablation and vertebral augmentation for palliation of painful spinal metastases. J Neurooncol. 2015;124(1):111-8. https://doi.org/10.1007/s1 1060-015-1813-2.

27. Zheng L, Chen Z, Sun M, Zeng H, Zuo D, Hua Y, Cai Z. A preliminary study of the safety and efficacy of radiofrequency ablation with percutaneous kyphoplasty for thoracolumbar vertebral metastatic tumor treatment. Med Sci Monit. 2014;4(20):556-63. https://doi.org/10.12659/MSM.889742.

28. Proschek D, Kurth A, Proschek P, VogI TJ, Mack MG. Prospective pilot-study of combined bipolar radiofrequency ablation and application of bone cement in bone metastases. Anticancer Res. 2009;29(7):2787-92.

29. Dabravolski D, Lahm A, Eßer J. Merk H (2015) Tumoren und Metastasen an der Wirbelsäule : Cavity/Coblation-Operation und Vertebro-/Kyphoplastie [Tumours and metastases of the spine : cavity/coblation surgery and vertebroplasty/kyphoplasty]. Orthopade. 2015;44(10):806-19. https://doi. org/10.1007/s00132-015-3138-4 (German).

30. Georgy BA. Bone cement deposition patterns with plasma-mediated radio-frequency ablation and cement augmentation for advanced metastatic spine lesions. AJNR Am J Neuroradiol. 2009;30(6):1197-202. https:// doi.org/10.3174/ajnr.A1548

31. Nakatsuka A, Yamakado K, Takaki H, Uraki J, Makita M, Oshima F, Takeda K. Percutaneous radiofrequency ablation of painful spinal tumors adjacent to the spinal cord with real-time monitoring of spinal canal temperature: a prospective study. Cardiovasc Intervent Radiol. 2009;32(1):70-5. https:// doi.org/10.1007/s00270-008-9390-9.

\section{Publisher's Note}

Springer Nature remains neutral with regard to jurisdictional claims in published maps and institutional affiliations. 